\title{
HISTAMINE IN THE BLOOD IN LEPROSY
}

\author{
DR. B. B. GoKhale
}

Department of Dermatology, Sassoon Hospitals, Poona, India.

At various national and international conferences there has been meticulous and prolonged discussion of the classification of leprosy, but none has been evolved to suit all opinions. There has been wide agreement about the existence and polar position of the lepromatous and tuberculoid forms, because each has a distinct clinical, pathological, and immunological picture. The immunology is not well understood. In the classical cases of tuberculoid leprosy the lepromin test is strongly positive, while in the lepromatous it is negative, and a theory was propounded that the positivity of the test indicates "allergy" and the negativity "anergy" (Rotberg, 1939; Davey, 1946). Still it is not quite clear whether positivity indicates allergy or potential allergy. Lepra reaction, which is an important and interesting phase which can supervene in the clinical course of leprosy is also thought by some to be of allergic nature. Various arguments for and against theories of allergy are put forward from time to time but remain speculative because of the failure to cultivate $M$. leprae in artificial media and to inoculate it successfully in experimental animals.

It has long been recognised that histamine plays a very important role in anaphylactic shock and in such human allergic reactions as urticaria and hay fever. Āke-Nitzen (1947) observed derangements of the histamine content of the blood in cases of arsphenamine dermatitis and of chronic recurrent urticaria. Hence it was thought worth while in leprosy to study the subject biochemically, and to estimate the histamine content of the blood.

\section{Material and Methods}

Most of the blood samples were collected by venipuncture from leprosy patients at the Sassoon Hospitals, Poona, and from blood donors to the blood bank at the same hospitals. All subjects came from a particular type of socio-economic group, so there was stratified sampling, and samples from the leprosy and non-leprosy group could reasonably be compared. The sampling was done at random, and the samples were taken after a vegetarian breakfast at about 10 a.m. and sent within the hour in an ice chest to the laboratories. Most of the samples were taken from males aet. 19 to 34 years and a few from non-pregnant adult females. Clinical records have been maintained of all subjects of the study, with haemograms and the results of serological tests for syphilis. There were 75 non-leprosy and 68 leprosy subjects.

The method used for the estimation of the histamine of the blood was a combination of those of McIntire et al. (1947) and Lubschez (1950), and the steps were as follows:-

1. Extraction of histamine from the sample in n-butanol; 
2. Adsorption of histamine from n-butanol on cotton-acidsuccinate;

3. Elution and colorimetric estimation of histamine in its purified form.

This microchemical method is suitable for the estimation of histamine base in amounts of the order of 0.01 to 0.1 microgram or more per cc. of sample. The substance extracted from the blood by this method was identified chemically as histamine. It was then tested for its pharmacological action in the experimental animal (the dog), where it behaved like histamine in producing a fall in blood pressure. Its effects were counteracted by the antihistaminic drug anthisan (Messrs. May \& Baker, India, Ltd.). Quantitative pharmacological and chemical estimations agreed well. The results of the study are presented in the Table.

\section{Results and Discussion}

In the non-leprosy cases the mean histamine level in the blood has been 4.84 microgram of histamine base per $100 \mathrm{cc}$. (all the values are expressed in terms of histamine base): in the leprosy subjects it was 7.01 microgram per $100 \mathrm{cc}$. (see Table). In order to assess the difference between the two groups, Student's t-test was applied to the values obtained and the value of " $t$ " was found to be highly significant (3.045). The histamine levels are significantly higher in leprosy subjects.

TABLE OF FINDINGS

\begin{tabular}{|c|c|c|c|c|c|}
\hline $\begin{array}{c}\text { No. of Subjects } \\
\text { and Type }\end{array}$ & $\begin{array}{c}\text { Means (in mi } \\
\text { rograms per } \\
100 \text { cc. blood) }\end{array}$ & $\begin{array}{l}\text { Standard } \\
\text { Deviation }\end{array}$ & Range & $\begin{array}{c}\text { Coefficient o } \\
\text { Dispersion }\end{array}$ & $\begin{array}{l}\text { Results of t-test } \\
\text { for significance } \\
\text { of difference of } \\
\text { means }\end{array}$ \\
\hline 78 non-lepros & 4.84 & 3.3 & $\begin{array}{l}0.4 \text { to } \\
13.6\end{array}$ & 0.68 & \\
\hline 68 leprosy & 7.01 & 5.2 & $\begin{array}{l}0.6 \text { to } \\
24.4\end{array}$ & 0.74 & $\begin{array}{l}\text { Highly } \\
\text { significant }\end{array}$ \\
\hline 21 lepromatous & 6.94 & 4.3 & $\begin{array}{l}1.3 \mathrm{to} \\
17.8\end{array}$ & 0.62 & $\begin{array}{l}\text { Slightly } \\
\text { significant }\end{array}$ \\
\hline 30 tuberculoid & 7.99 & 6.2 & $\begin{array}{l}0.5 \text { to } \\
24.4\end{array}$ & 0.77 & $\begin{array}{l}\text { Highly } \\
\text { significant }\end{array}$ \\
\hline 17 other types & 5.5 & 3.6 & $\begin{array}{l}1.3 \mathrm{to} \\
12.0\end{array}$ & 0.65 & $\begin{array}{l}\text { Not } \\
\text { significant }\end{array}$ \\
\hline
\end{tabular}


The respective means and standard deviations (see Table) were calculated for the leprosy types, of which there were 30 tuberculoid, 21 lepromatous, and 17 maculoanaesthetic or dimorphous. The application of the t-test to their values showed that the significant difference between the means of the two groups was mainly due to the tuberculoid type; this finding is of particular interest in view of the fact of the strong positivity of the lepromin test in tuberculoid leprosy.

Though this study of a representative group of leprosy cases showed a significantly higher blood histamine level than in the group of normal cases, this was as a group, and great variation was found in individual cases. This suggests the value of a linear study of individual examples of the leprosy types in different clinical phases of the disease, such as reaction or quiescence. Ake-Nitzen carried out such a study in cases of chronic urticaria, with illuminating results, for in his cases the histamine content of the blood dropped when the symptoms increased and rose when the cases improved.

\section{Summary}

The histamine content of the blood in leprosy subjects as a group has been found to be higher than in non-leprosy subjects. The tuberculoid type showed the more markedly significant higher levels; as in this type the lepromin reaction is strongly positive, the finding is of great interest.

\section{Acknowledgements}

This study was sponsored by the Indian Council of Medical Research and carried out from June 1953 to March 1955. The author expresses his thanks to the authorities of the Council; the staff of the National Chemical Laboratories, Poona, and of the Department of Pharmacology, G.S. Medical College, Bombay, and to colleagues at the Sassoon Hospitals and B.J. Medical College, Poona; also to Prof. S. K. Gokhale at G. S. Medical College, Bombay, Sri V. M. Dandekar of Gokhale Institute of Politics and Economics, Dr. N. K. Bhide, Dr. Shivraman, Sri and Mrs. S. S. Pande of Poona, for the help they have given from time to time.

\section{REFERENCES}

ĀKe-NitZen. Acta Derm. vener. 17 suppl. 17, 1947, p. 53.

lbid, 27, 1947, pp. 521-527.

Davey, T. F., Leprosy Rev., 17, 1946, p. 42 and 75.

Haworth, E. and Macdonald, A. D., J. Hyg. 37, 1937, p. 234.

Lubschez, R., J. Biol. Chem. 1950, 183, p. 731.

MCIntiRe, F. C., Roth, L. W., and Shaw, J. L., J. Biol. Chem. 1947, 170, p. 537.

Rotberg, A., Leprosy Rev., 1939, 10, p. 130.

Roze, B. and Browne, J. S. L., Proc. Soc. Exp. Biol. Med. 1940, 44, p. 182.

Valentine, W. N., Pearce, M. L., Lawrence, J. S., Blood, 1950, 5, p. 623. 